\title{
Endoscopic ultrasound-guided rendezvous ERCP using a steerable access device
}

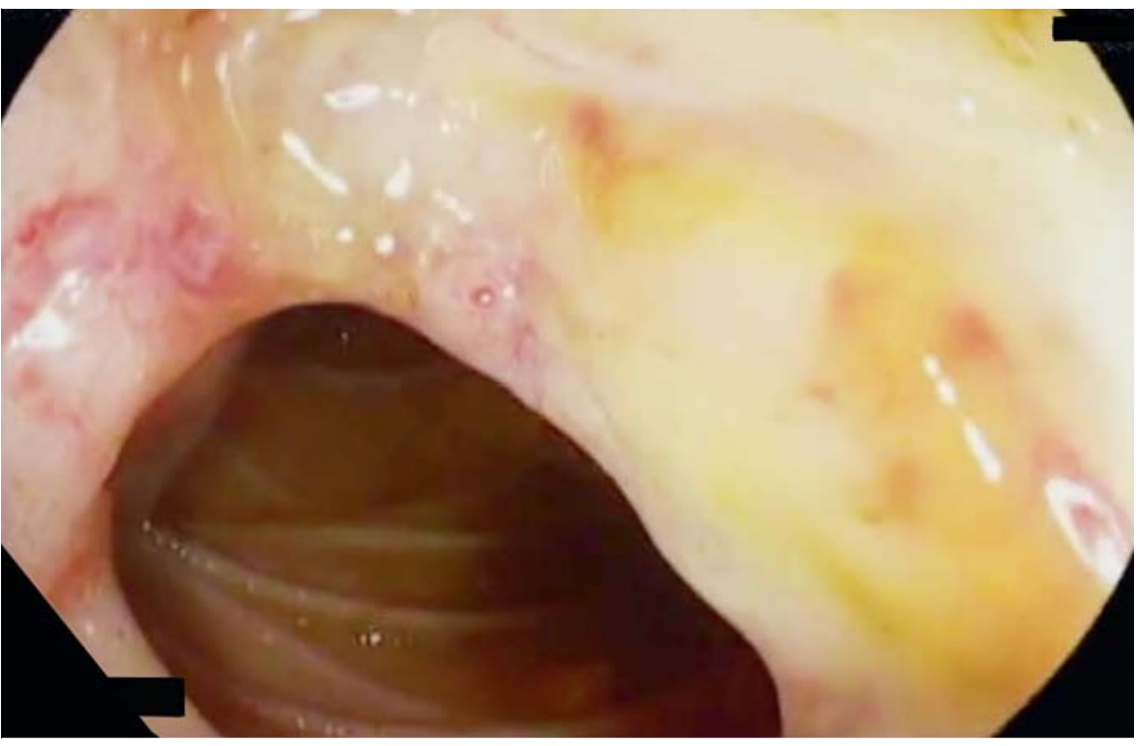

- Fig. 1 Endoscopic view of the ulcer distal to the hematoma.

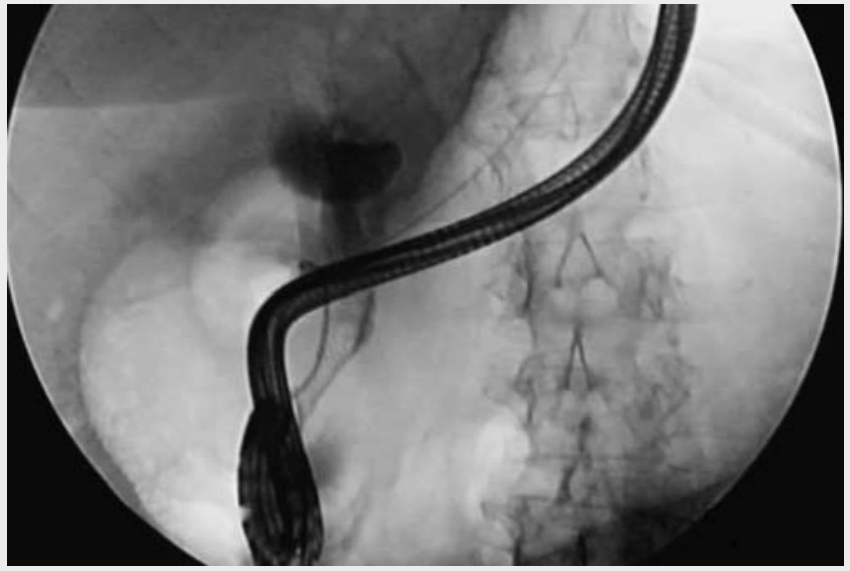

Video 1 Endoscopic ultrasound-guided rendezvous endoscopic retrograde cholangiopancreatography using a steerable access device.

A 77-year-old woman with history of lung adenocarcinoma and bone metastasis presented with intractable nausea, nonbloody emesis, and abdominal pain. The patient was taking high doses of nonsteroidal anti-inflammatory drugs for pain from bone metastasis. Computed tomography demonstrated a duode- nal stricture and dilated common bile duct. Liver function tests showed raised bilirubin and alkaline phosphatase.

Upper endoscopy showed a large obstructive hematoma just distal to the duodenal bulb. On further inspection, a large ulcer ( $\triangleright$ Fig. 1) was found at the 12 to 1 o'clock position. The ulcer was biop-

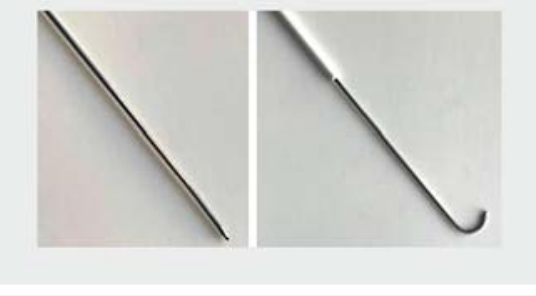

- Fig. 2 The steerable access catheter in its curved profile once the sharp stylet on the left is removed.

sied to confirm the etiology (i.e. benign or malignant). As the stricture prevented the duodenoscope from progressing into a position from which conventional retrograde cannulation could be performed, a rendezvous endoscopic ultrasound (EUS)-guided endoscopic retrograde cholangiopancreatography was performed using a steerable access device (> Fig. 2, $>$ Video 1 ).

The bile duct was located using EUS and then punctured from the duodenal bulb using the sharp stylet on the access device ( Fig.3). Contrast was injected and a 0.025 -inch guidewire was passed into the second and third parts of the duodenum, with the catheter in its predetermined curvature to allow for easier access ( $\triangleright$ Fig. 4 ). A gastroscope was then used to grasp the guidewire, which was pulled out through the mouth. The biliary orifice was dilated to $6 \mathrm{~mm}$ using a through-the-scope balloon. Once dilation was completed, a $10 \times$ $40 \mathrm{~mm}$ fully covered metal stent was deployed by retroflexing the gastroscope and leaving the guidewire in place to allow for added pushability ( $>$ Fig.5).

After stent deployment there was significant drainage of the biliary tree. The ulcer was confirmed as benign, and the patient was started on proton pump inhibitors. Her liver enzyme levels returned to normal soon after the operation, and she was invited to return 6 months later for stent removal.

Endoscopy_UCTN_Code_TTT_1AR_2AK 


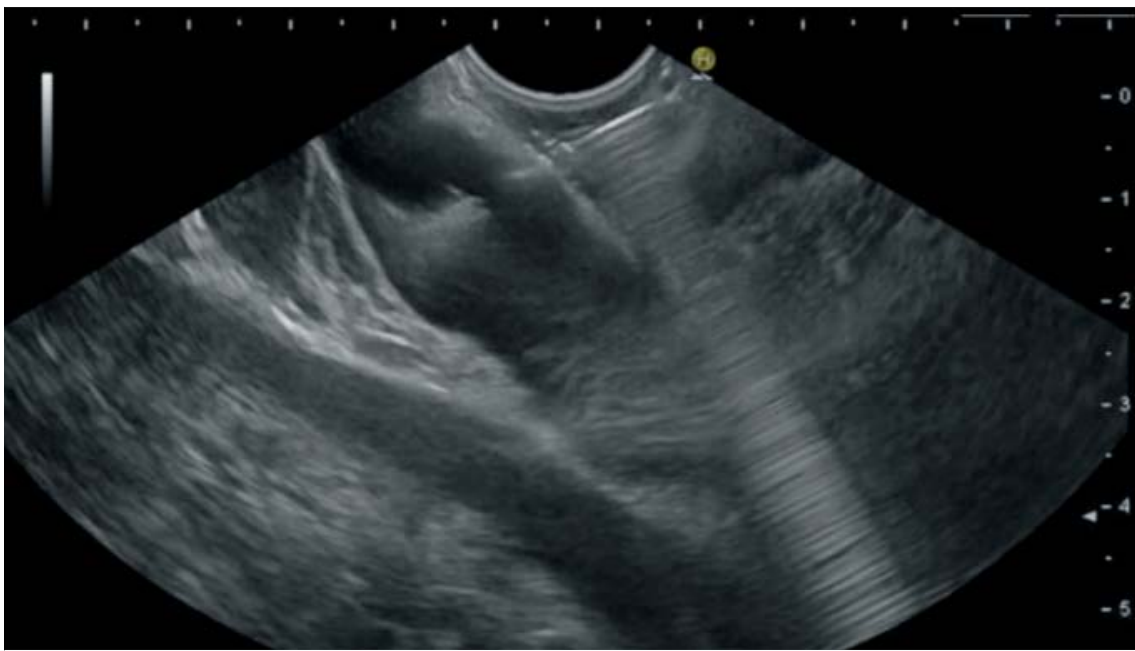

- Fig. 3 The steerable access catheter in the bile duct with the tip toward the liver.

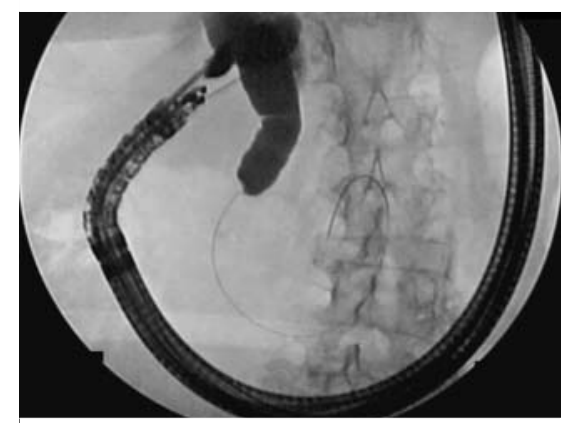

Fig. 4 Cholangiogram showing contrast in the cystic duct as well as the common hepatic duct and common bile duct, with a 0.025 -inch guidewire catheter passed through the stricture into the third and fourth parts of the duodenum.

\section{Competing interests}

Dr. Kumbhari is a consultant for Apollo Endosurgery, Boston Scientific, Medtronic, FuijiFilm, Pentax Medial, Obalon, and ReShape Life Sciences, and has received research support from Erbe and Apollo Endosurgery. Dr. Khashab is a consultant for Boston Scientific, Medtronic, and Olympus. All other authors declare that they have no conflict of interest.

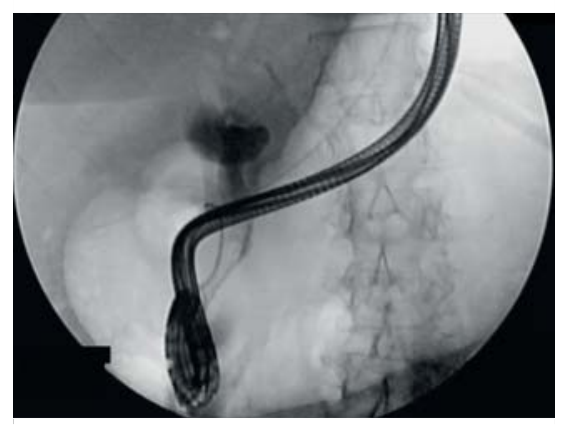

- Fig. 5 The retroflexed position of the gastroscope during stent deployment. Note the guidewire was not advanced into the intrahepatic ducts and remained through the duodenal bulb to allow tension to be placed on it to assist in reaching the optimal stent deployment position.

The authors

\section{Mohamad K. Marrache, Abdulhameed Al-}

Sabban, Mohamad Itani, Jad Farha, Lea Fayad, Mouen A. Khashab, Vivek Kumbhari Department of Gastroenterology and Hepatology, The Johns Hopkins University, Baltimore, Maryland, United States

Corresponding author

\section{Vivek Kumbhari, MD, PhD}

Department of Gastroenterology and Hepatology, The Johns Hopkins University, 1800 Orleans Street, Suite 7125B, Baltimore, Maryland 21202, United States

Fax: +1-410-933-7495

vkumbhari@gmail.com

\section{Bibliography}

DOI https://doi.org/10.1055/a-1127-2820

Published online: 27.3.2020

Endoscopy 2020; 52: E355-E356

(c) Georg Thieme Verlag KG

Stuttgart · New York

ISSN 0013-726X

\section{ENDOSCOPY E-VIDEOS \\ https://eref.thieme.de/e-videos}

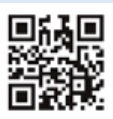

Endoscopy E-Videos is a free access online section, reporting on interesting cases and new

techniques in gastroenterological endoscopy. All papers include a high quality video and all contributions are freely accessible online.

This section has its own submission website at

https://mc.manuscriptcentral.com/e-videos 